\title{
Copper Perchlorate Hexahydrate: An Efficient Catalyst for the Green Synthesis of Polyhydroquinolines under Ultrasonication
}

\author{
Saurabh Puri, ${ }^{1}$ Balbir Kaur, ${ }^{1}$ Anupama Parmar, ${ }^{2}$ and Harish Kumar ${ }^{3}$ \\ ${ }^{1}$ Department of Chemistry, Punjabi University, Patiala 147002, India \\ ${ }^{2}$ Post Graduate Department of Chemistry, M.M. Modi College Patiala, Patiala 147001, India \\ ${ }^{3}$ Department of Chemistry, Sant Longowal Institute of Engineering and Technology, Longowal 148106, India
}

Correspondence should be addressed to Harish Kumar, hk67@rediffmail.com

Received 26 January 2011; Accepted 28 February 2011

Academic Editors: J. Drabowicz, P. M. T. Ferreira, and I. Tellitu

Copyright () 2011 Saurabh Puri et al. This is an open access article distributed under the Creative Commons Attribution License, which permits unrestricted use, distribution, and reproduction in any medium, provided the original work is properly cited.

\begin{abstract}
Copper perchlorate hexahydrate as an efficient catalyst was used for the synthesis of polyhydroquinolines by four-component condensation reaction of aldehyde, ethyl acetoacetate, dimedone, and ammonium acetate in excellent yields and short reaction times at room temperature under ultrasound irradiation. This novel synthetic method is especially favoured because it provides a synergy between copper perchlorate hexahydrate and ultrasound irradiation which offers the advantages of high yields, short reaction times, simplicity, and easy workup compared to the conventional methods reported in the literature.
\end{abstract}

\section{Introduction}

Multicomponent reactions (MCRs) have emerged as an efficient and dominant tool in modern synthetic organic chemistry allowing the facile creation of several new bonds in a one-pot reaction. Clearly for multistep synthetic procedures, the number of reactions and purification steps is among the most significant criteria for the efficiency and feasibility of the process and should be as low as possible. Therefore research in academia and industry has increasingly emphasized the use of MCRs as well as domino reaction sequences for a broad range of products $[1,2]$. Ultrasound is widely used for improving the traditional reactions that use expensive reagents, strongly acidic conditions, long reaction times, and high temperatures unsatisfactory yields [3]. 4-substituted 1,4-dihydropyridines (1,4-DHPs) are well known as $\mathrm{Ca}^{2+}$ channel blockers and emerged as one of the most important classes of drugs for the treatment of cardiovascular diseases, including hypertension $[4,5]$. In view of the importance of polyhydroquinoline derivatives, many classical methods for their synthesis were reported [611] using conventional heating and refluxing approaches in the presence of an organic solvent. These methods, however, involve long reaction times, harsh reaction conditions, and the use of a large quantity of volatile organic solvents and generally lead to low yields. Therefore, it is necessary to develop an efficient and versatile method for the preparation of 1,4-dihydropyridines, and the progress in this field has been recently remarkable including the promotion of microwave [12], TMSCl [13], ionic liquids [14, 15], polymers $[16,17]$, and $\mathrm{Yb}(\mathrm{OTf})_{3}[18]$. The multicomponent reactions are powerful tools in the modern drug discovery process and allow fast, automated, and high-throughput generation of organic compounds [19]. The possibility of performing multicomponent reactions under solvent-free conditions with a heterogeneous catalyst could enhance their efficiency from an economic as well as an ecological point of view. In recent years heterogeneous catalysts have been gaining more importance due to environmental-economic factors. The catalyst is generally of low cost and can be easily handled or removed. Herein, we would like to report an efficient and greener route for the synthesis of polyhydroquinolines from the reaction of readily available and nonexpensive starting materials (dimedone, aromatic aldehydes, ethyl acetoacetate, ammonium acetate, and copper perchlorate hexahydrate) under solvent-free conditions using ultrasonic irradiation. 


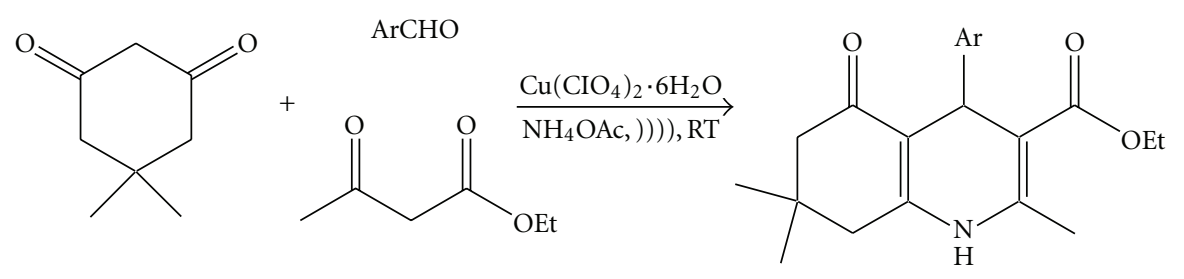

Scheme 1: Solvent-free synthesis of polyhydroquinolines 1a-1l under ultrasound irradiation.

\section{Experimental}

2.1. Chemicals and Apparatus. Liquid carbonyl compounds were purified by distillation before use. All melting points recorded are uncorrected, open capillary measurements, using sulphuric acid bath. NMR spectra were recorded on AL-300F (Bruker) FT NMR spectrophotometer using tetramethylsilane (TMS) as internal standard. All solvents were reagent grade and used as received. The reactions were performed in open vessels.

2.2. General Procedure for the Synthesis of Polyhydroquinoline Derivatives. A mixture of aryl aldehyde $(1 \mathrm{mmol}), 5,5-$ dimethyl-1,3-cyclohexanedione (1 mmol), ethyl acetoacetate $(1 \mathrm{mmol})$ and ammonium acetate $(1 \mathrm{mmol})$ was added to $\mathrm{Cu}\left(\mathrm{ClO}_{4}\right)_{2} \cdot 6 \mathrm{H}_{2} \mathrm{O}(15 \mathrm{~mol} \%)$, and the reaction mixture was exposed to ultrasound irradiation 20-40 min (completion of the reactions was monitored by TLC). After the completion of reaction, the reaction mixture was diluted with ethyl alcohol and stirred for 10 minutes at $80^{\circ} \mathrm{C}$. The residue was filtered hot and kept at room temperature, and the resulting crystalline product was collected by filtration. The product formed was recrystallized from ethanol. The formation of products was confirmed by comparing the melting points and NMR data with authentic samples and literature data.

\subsection{Selected Spectral Data of the Selected Products}

2,7,7-Trimethyl-5-oxo-4-phenyl-1,4,5,6,7,8-hexahydroquinoline-3-carboxylic acid ethyl ester (1a). mp 202-204 ${ }^{\circ} \mathrm{C}$. IR (KBr) $\mathrm{cm}^{-1}: 3287,3077,2964,1696,1610 .{ }^{1} \mathrm{H}-\mathrm{NMR}$ $\left(\mathrm{CDCl}_{3}\right) \delta: 0.93(3 \mathrm{H}, \mathrm{s}), 1.06(3 \mathrm{H}, \mathrm{s}), 1.20(3 \mathrm{H}, \mathrm{t}, J=7.1 \mathrm{~Hz})$, $2.12-2.28(4 \mathrm{H}, \mathrm{m}), 2.34(3 \mathrm{H}, \mathrm{s}), 4.05(2 \mathrm{H}, \mathrm{q}, J=7.1 \mathrm{~Hz})$, $5.06(1 \mathrm{H}, \mathrm{s}), 6.63(1 \mathrm{H}, \mathrm{s}), 7.07-7.12(1 \mathrm{H}, \mathrm{m}), 7.17-7.22(2 \mathrm{H}$, m), 7.27-7.32 (2H, m).

4-(4-Methoxyphenyl)-2,7,7-trimethyl-5-oxo-1,4,5,6,7,8-hexahydroquinoline-3-carboxylic acid ethyl ester (1b). mp 257$258^{\circ} \mathrm{C}$. IR (KBr) cm ${ }^{-1}: 3276,2956,1703,1648,1606,1496$, $1381,1215,1031,765 .{ }^{1} \mathrm{H}-\mathrm{NMR}\left(\mathrm{CDCl}_{3}+\mathrm{DMSO}_{6}\right) \delta: \delta=$ $0.95(3 \mathrm{H}, \mathrm{s}), 1.09(3 \mathrm{H}, \mathrm{s}), 1.21(3 \mathrm{H}, \mathrm{t}, J=7.2 \mathrm{~Hz}), 2.01-2.10$ $(4 \mathrm{H}, \mathrm{m}), 2.30(3 \mathrm{H}, \mathrm{s}), 3.70(3 \mathrm{H}, \mathrm{s}), 4.00(2 \mathrm{H}, \mathrm{q}, J=7.2 \mathrm{~Hz})$, $4.80(1 \mathrm{H}, \mathrm{s}), 6.65(2 \mathrm{H}, \mathrm{d}, J=7.3 \mathrm{~Hz}), 7.10(2 \mathrm{H}, \mathrm{d}, J=7.3 \mathrm{~Hz})$, $8.65(1 \mathrm{H}, \mathrm{s})$.

4-(4-Fluorophenyl)-2, 7,7-trimethyl-5-oxo-1, 4, 5, 6, 7, 8-hexahydroquinoline-3-carboxylic acid ethyl ester (1f). $\mathrm{mp}$ 184$185^{\circ} \mathrm{C}$. IR $(\mathrm{KBr}) \mathrm{cm}^{-1}$ : 3292, 2959, 1696, 1649, 1608, 1487, 1380, 1219, 1025, 764. ${ }^{1} \mathrm{H}-\mathrm{NMR}\left(\mathrm{CDCl}_{3}\right) \delta: 0.92(3 \mathrm{H}, \mathrm{s})$,
TABLE 1: Effect of amounts of catalyst, copper perchlorate hexahydrate with or without sonication for synthesis of 2,7,7-Trimethyl5-oxo-4-phenyl-1,4,5,6,7,8-hexahydroquinoline-3-carboxylic acid ethyl ester.

\begin{tabular}{lccccc}
\hline Entry & $\mathrm{Cu}\left(\mathrm{ClO}_{4}\right)_{2} \cdot 6 \mathrm{H}_{2} \mathrm{O}$ & \multicolumn{2}{c}{ With sonication } & \multicolumn{2}{c}{ Without sonication } \\
& mol\% & Yield & Time & Yield & Time \\
$(\%)$ & $(\mathrm{min})$ & $(\%)$ & min) \\
\hline$(1)$ & 0 & Nil & 90 & Nil & 90 \\
$(2)$ & 5 & 24 & 60 & 10 & 70 \\
$(3)$ & 10 & 57 & 40 & 23 & 55 \\
$(4)$ & 15 & 90 & 20 & 33 & 40 \\
$(5)$ & 20 & 90 & 20 & 33 & 40 \\
\hline
\end{tabular}

$1.07(3 \mathrm{H}, \mathrm{s}), 1.18(3 \mathrm{H}, \mathrm{t}, J=7.3 \mathrm{~Hz}), 2.13-2.25(4 \mathrm{H}, \mathrm{m}), 2.38$ $(3 \mathrm{H}, \mathrm{s}), 4.05(2 \mathrm{H}, \mathrm{q}, J=7.33 \mathrm{~Hz}), 5.02(1 \mathrm{H}, \mathrm{s}), 5.8(1 \mathrm{H}, \mathrm{s})$, 6.85-6.89 (2H, m), 7.23-7.27 (2H, m).

4-(2-Chlorophenyl)-2, 7,7-trimethyl-5-oxo-1, 4, 5, 6, 7, 8-hexahydroquinoline-3-carboxylic acid ethyl ester (1k). mp 209$210^{\circ} \mathrm{C}$. IR (KBr) cm $\mathrm{cm}^{-1}: 3063,2956,1721,1640,1611,1467$, $1384,1227,1021,745 .{ }^{1} \mathrm{H}-\mathrm{NMR}\left(\mathrm{CDCl}_{3}+\mathrm{DMSO}_{6} \mathrm{~d}_{6}\right) \delta: \delta=$ $0.95(3 \mathrm{H}, \mathrm{s}), 1.05(3 \mathrm{H}, \mathrm{s}), 1.20(3 \mathrm{H}, \mathrm{t}, J=7.2 \mathrm{~Hz}), 2.01-2.21$ $(4 \mathrm{H}, \mathrm{m}), 2.40(3 \mathrm{H}, \mathrm{s}), 4.05(2 \mathrm{H}, \mathrm{q}, J=7.2 \mathrm{~Hz}), 4.60(1 \mathrm{H}, \mathrm{s})$, 7.10-7.30 (4H, m), $7.60(1 \mathrm{H}, \mathrm{s})$.

\section{Results and Discussion}

In continuation of our work to develop new and ecofriendly synthetic methodologies [20-23], herein, we report an expedient protocol for the synthesis of polyhydroquinolines. (Scheme 1). The reactions were carried out at room temperature for $20-40 \mathrm{~min}$ in the presence of $15 \mathrm{~mol} \%$ of the copper perchlorate hexahydrate at $35 \mathrm{kHz}$ under ultrasound irradiation. To determine the amount of the catalyst in this reaction, benzaldehyde was used as one of the reactants for $20 \mathrm{~min}$ under ultrasound irradiation in the presence of varying mol\% of the copper perchlorate hexahydrate separately. The best results were obtained using $15 \mathrm{~mol} \%$ of the catalyst. Using lesser amount of the catalyst resulted in lower yields, while higher amount of the catalyst did not affect reaction times and yields. In the absence of the catalyst, the yield was found to be very low. To verify the effect of ultrasound irradiation on this procedure, the synthesis of polyhydroquinolines was done in the presence of varying mol\% of the copper perchlorate hexahydrate with and without ultrasound irradiation (Table 1). In all 
TABle 2: Copper perchlorate hexahydrate catalyzed solvent-free synthesis of polyhydroquinolines $1 \mathrm{a}-11$ under ultrasound irradiation.

\begin{tabular}{|c|c|c|c|c|c|}
\hline Entry & Products & $\mathrm{Ar}$ & $\begin{array}{l}\text { Time } \\
(\mathrm{min})\end{array}$ & $\begin{array}{c}\text { Yield } \\
(\%)\end{array}$ & $\begin{array}{c}\mathrm{mp}{ }^{\circ} \mathrm{C} \\
\left(\text { Lit } \mathrm{mp}{ }^{\circ} \mathrm{C}\right)\end{array}$ \\
\hline (1) & 1a & $\mathrm{C}_{6} \mathrm{H}_{5}$ & 20 & 96 & $\begin{array}{c}203-204 \\
(202-204)^{16}\end{array}$ \\
\hline (2) & $1 b$ & $4-\mathrm{MeOC}_{6} \mathrm{H}_{4}$ & 25 & 97 & $\begin{array}{c}257-258 \\
(257-259)^{16}\end{array}$ \\
\hline (3) & $1 \mathrm{c}$ & $4-\mathrm{ClC}_{6} \mathrm{H}_{4}$ & 25 & 95 & $\begin{array}{c}244-245 \\
(245-246)^{12}\end{array}$ \\
\hline (4) & $1 d$ & $4-\mathrm{NO}_{2} \mathrm{C}_{6} \mathrm{H}_{4}$ & 35 & 88 & $\begin{array}{c}242-243 \\
(242-244)^{12}\end{array}$ \\
\hline (5) & le & $3-\mathrm{NO}_{2} \mathrm{C}_{6} \mathrm{H}_{4}$ & 35 & 86 & $\begin{array}{c}176-177 \\
(177-178)^{5}\end{array}$ \\
\hline (6) & $1 \mathrm{f}$ & $4-\mathrm{FC}_{6} \mathrm{H}_{4}$ & 25 & 94 & $\begin{array}{c}184-185 \\
(184-186)^{16}\end{array}$ \\
\hline (7) & $1 \mathrm{~g}$ & $4-\mathrm{OHC}_{6} \mathrm{H}_{4}$ & 40 & 89 & $\begin{array}{c}232-233 \\
(232-234)^{16}\end{array}$ \\
\hline (8) & $1 \mathrm{~h}$ & $2-\mathrm{NO}_{2} \mathrm{C}_{6} \mathrm{H}_{4}$ & 25 & 90 & $\begin{array}{c}207-208 \\
(206-208)^{5}\end{array}$ \\
\hline (9) & li & $4-\mathrm{BrC}_{6} \mathrm{H}_{4}$ & 30 & 91 & $\begin{array}{c}254-255 \\
(253-255)^{16}\end{array}$ \\
\hline (10) & $1 \mathrm{j}$ & $3-\mathrm{ClC}_{6} \mathrm{H}_{4}$ & 25 & 93 & $\begin{array}{c}231-232 \\
(230-232)^{22}\end{array}$ \\
\hline (11) & $1 \mathrm{k}$ & $2-\mathrm{ClC}_{6} \mathrm{H}_{4}$ & 25 & 93 & $\begin{array}{c}209-210 \\
(208-210)^{12}\end{array}$ \\
\hline (12) & 11 & $4-\mathrm{MeC}_{6} \mathrm{H}_{4}$ & 25 & 93 & $\begin{array}{c}260-261 \\
(260-261)^{16}\end{array}$ \\
\hline
\end{tabular}

reactions, it was found that the use of ultrasound leads to faster reaction and higher yields. So it shows that use of the ultrasound improves the rate of reaction and also yields of products formed. A wide range of substituted aldehydes were used to give excellent yield of products (1a-1l) (Table 2). Reactions were also performed using ethanol as a solvent, but the yield was less than the in solvent-free conditions.

\section{Conclusion}

We have introduced a new and highly efficient catalyst, copper perchlorate hexahydrate, for the synthesis of polyhydroquinolines. The significant aspects of our methodology are efficiency, generality, high yield, short reaction time, low cost, cleaner greener reaction profile, ease of product isolation, the use of alternative source of energy, and ultimately conformity with the green chemistry protocols.

\section{References}

[1] A. Domling and I. Ugi, "Multicomponent reactions with isocyanides," Angewandte Chemie International Edition, vol. 39, p. 3168, 2000.

[2] L. Yu, B. Chen, and X. Huang, "Multicomponent reactions of allenes, diaryl diselenides, and nucleophiles in the presence of iodosobenzene diacetate: direct synthesis of 3-functionalized2-arylselenyl substituted allyl derivatives," Tetrahedron Letters, vol. 48, no. 6, pp. 925-927, 2007.
[3] J. S. Yadav, B. V. S. Reddy, K. B. Reddy, K. S. Raj, and A. R. Prasad, "Ultrasound-accelerated synthesis of 3,4-dihydropyrimidin-2 $(1 \mathrm{H})$-ones with ceric ammonium nitrate," Journal of the Chemical Society. Perkin Transactions, vol. 1, no. 16, pp. 1939-1941, 2001.

[4] F. Bossert, H. Meyer, and E. Wehinger, "4-aryldihydropyridines, a new class of highly active calcium antagonists," Angewandte Chemie International Edition, vol. 20, no. 9, pp. 762-769, 1981.

[5] H. Nakayama and Y. Kasoaka, "Chemical Identification of Binding Sites for Calcium Channel Antagonists," Heterocycles, vol. 42, no. 2, pp. 901-909, 1996.

[6] A. Hantzsch, "Ueber die synthese pyridinartiger verbindungen aus acetessigäther und aldehydammoniak," Ann's Chemistry, vol. 1, p. 215, 1882.

[7] J. B. Sainani, A. C. Shah, and V. P. Arya, "Formation of 1,4,5,6,7,8-Hexahydro-pyrido(4,3-b)pyridine by Hantzsch synthesis," Indian Journal of Chemistry B, vol. 33, p. 526, 1994.

[8] V. K. Ahluwalia, B. Goyal, and U. Das, "One-pot Syntheses of 5-Oxo-1,4,5,6,7,8-hexahydroquinolines and Pyrimido[4,5b] quinolines using Microwave Irradiation and Ultrasound," Journal of Chemical Research S, no. 7, p. 266, 1997.

[9] S. Margarita, O. Estael, V. Yamila et al., "A joint experimental and theoretical structural study of novel substituted 2,5dioxo-1,2,3,4,5,6,7,8-octahydroquinolines," Tetrahedron, vol. 55, no. 3, pp. 875-884, 1999.

[10] V. K. Ahluwalia, B. Goyal, U. Das et al., "One-pot syntheses of 5-oxo-1,4,5,6,7,8-hexahydroquinolines and pyrimido[4,5b] quinolines using microwave irradiation and ultrasound," Journal of Chemical Research, vol. 7, p. 1501, 1997.

[11] V. K. Ahluwalia and B. Goyal, "One-pot synthesis of 4-aryl5-oxo-1,4,5,6,7,8-hexahydro-2,7,7-trimethylquinoline-3carboxylates," Indian Journal of Chemistry B, vol. 35, no. 10, pp. 1021-1025, 1996.

[12] S.-J. Tu, J.-F. Zhou, X. Deng et al., "One-step synthesis of 4arylpolyhydroquinoline derivatives using microwave irradiation," The Journal of Organic Chemistry, vol. 21, no. 4, pp. 313316, 2001.

[13] G. Sabitha, G. S. K. K. Reddy, CH. S. Reddy, and J. S. Yadav, "A novel TMSI-mediated synthesis of Hantzsch 1,4-dihydropyridines at ambient temperature," Tetrahedron Letters, vol. 44, no. 21, pp. 4129-4131, 2003.

[14] S. J. Ji, Z. Q. Jiang, J. Lu, and T. P. Loa, "Facile ionic liquids-promoted one-pot synthesis of polyhydroquinoline derivatives under solvent free conditions," Synlett, no. 5, pp. 831-835, 2004.

[15] R. Sridhar and P. T. Perumal, "A new protocol to synthesize 1,4-dihydropyridines by using 3,4,5-trifluorobenzeneboronic acid as a catalyst in ionic liquid: synthesis of novel 4-(3-carboxyl-1H-pyrazol-4-yl)-1,4-dihydropyridines," Tetrahedron, vol. 61, no. 9, pp. 2465-2470, 2005.

[16] J. G. Breitenbucher and G. Figliozzi, "Solid-phase synthesis of 4-aryl-1,4-dihydropyridines via the Hantzsch three component condensation," Tetrahedron Letters, vol. 41, no. 22, pp. 4311-4315, 2000.

[17] A. Dondoni, A. Massi, E. Minghini, and V. Bertolasi, "Multicomponent Hantzsch cyclocondensation as a route to highly functionalized 2- and 4-dihydropyridylalanines, 2and 4-pyridylalanines, and their N-oxides: preparation via a polymer-assisted solution-phase approach," Tetrahedron, vol. 60, no. 10, pp. 2311-2326, 2004.

[18] L. M. Wang, J. Sheng, L. Zhang et al., "Facile Yb(OTf) promoted one-pot synthesis of polyhydroquinoline derivatives through Hantzsch reaction," Tetrahedron, vol. 61, no. 6, pp. 1539-1543, 2005. 
[19] L. Weber, "The application of multi-component reactions in drug discovery," Current Medicinal Chemistry, vol. 9, no. 23, pp. 2085-2093, 2002.

[20] A. Parmar and H. Kumar, "Iron (III) perchlorate adsorbed on silica gel: a reagent for organic functional group transformations," Synthetic Communications, vol. 37, no. 14, pp. 23012308, 2007.

[21] A. Parmar and H. Kumar, "Ultrasound promoted $\mathrm{ZrCl}$ catalyzed rapid synthesis of substituted 1,2,3,4-tetrahydropyrimidine-2-ones in solvent or dry media," Ultrasonics Sonochemistry, vol. 15, no. 2, pp. 129-132, 2008.

[22] S. Puri, B. Kaur, A. Parmar, and H. Kumar, "Ultrasoundpromoted greener synthesis of $2 \mathrm{H}$-chromen-2-ones catalyzed by copper perchlorate in solventless media," Ultrasonics Sonochemistry, vol. 16, no. 6, pp. 705-707, 2009.

[23] S. Puri, B. Kaur, A. Parmar, and H. Kumar, "Ultrasound promoted $\mathrm{Cu}(\mathrm{Clo} 4) 2$ catalyzed rapid synthesis of substituted 1,2,3,4- Tetrahydropyrimidine-2-ones \& Hantzsch 1,4dihydropyridines in dry media," Hetero Community, vol. 15, no. 1 , pp. 51-56, 2009. 


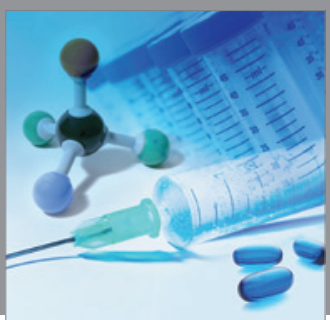

International Journal of

Medicinal Chemistry

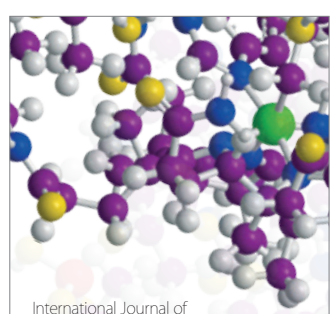

Carbohydrate Chemistry

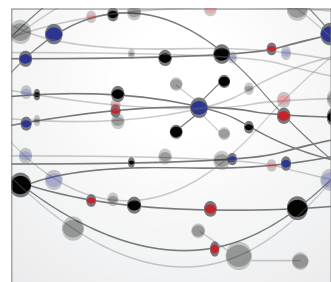

The Scientific World Journal
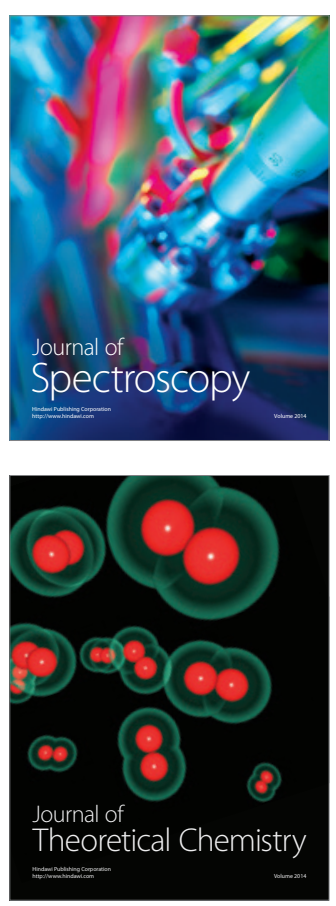
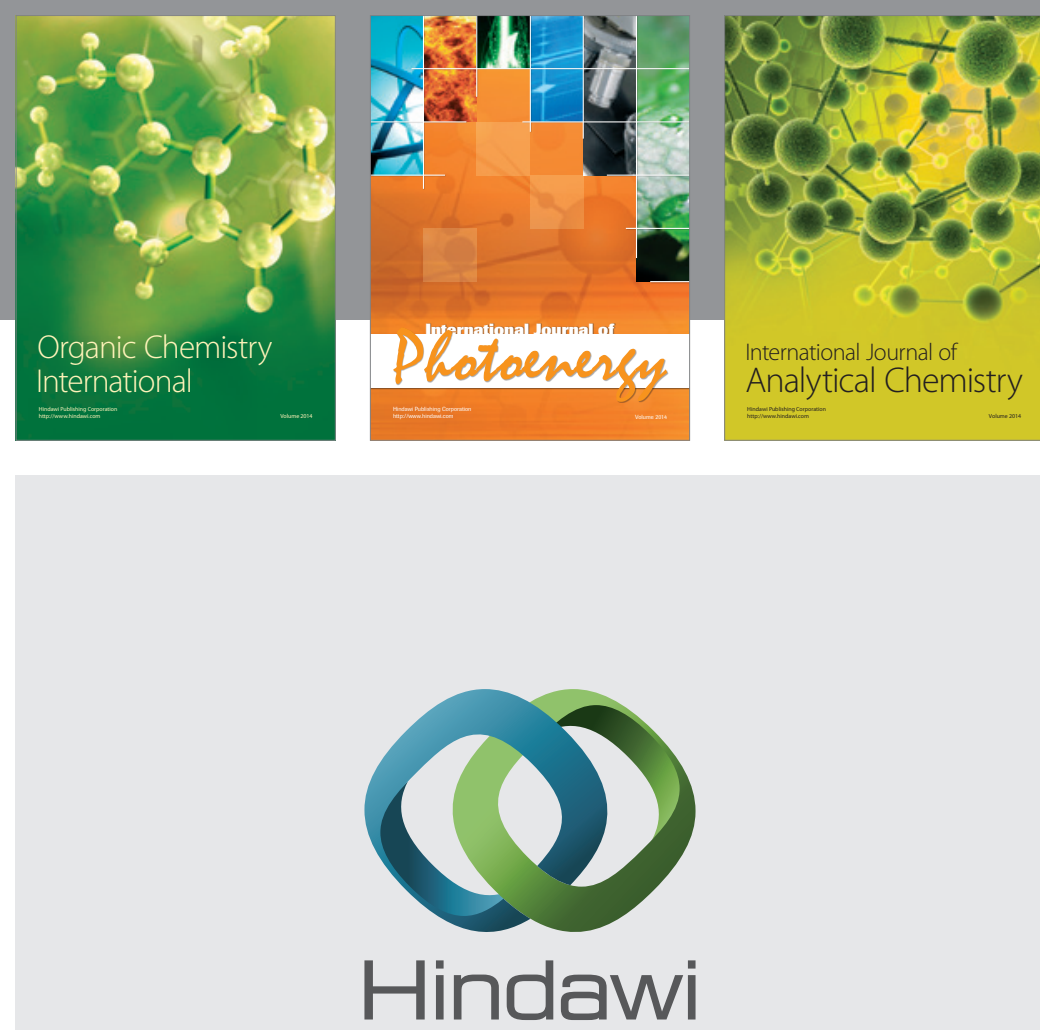

Submit your manuscripts at

http://www.hindawi.com
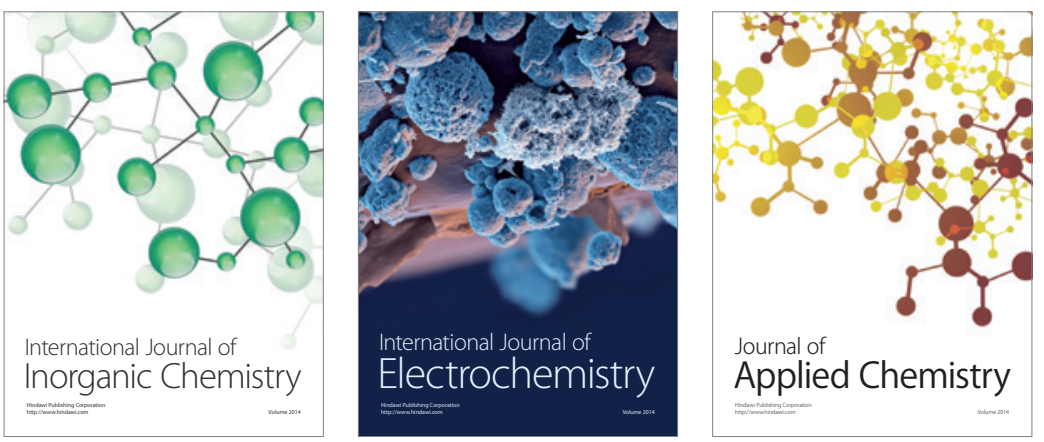

Journal of

Applied Chemistry
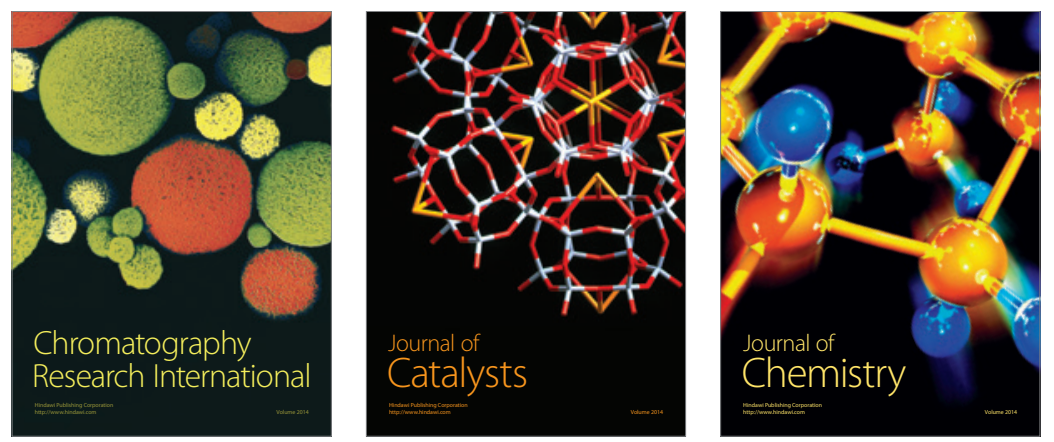
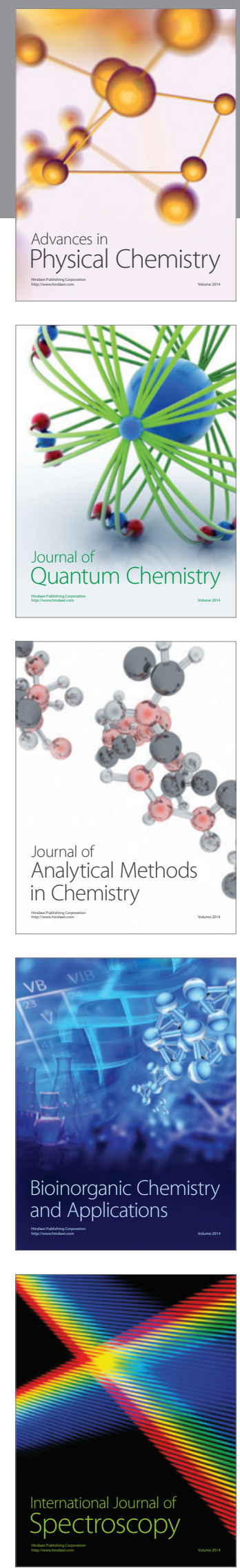